\title{
Review: Epigenetics, developmental programming and nutrition in herbivores
}

\author{
P. Chavatte-Palmer ${ }^{1 \dagger}$, M. A. Velazquez ${ }^{2}$, H. Jammes ${ }^{1}$ and V. Duranthon ${ }^{1}$ \\ ${ }^{1}$ UMR BDR, INRA, ENVA, Université Paris Saclay, 78350 Jouy en Josas, France; ${ }^{2}$ School of Natural and Environmental Sciences, Newcastle University, Newcastle upon \\ Tyne NE1 $4 L E$, UK
}

(Received 6 January 2018; Accepted 30 March 2018; First published online 24 August 2018)

\begin{abstract}
Epidemiological studies in humans and animal models (including ruminants and horses) have highlighted the critical role of nutrition on developmental programming. Indeed, it has been demonstrated that the nutritional environment during the periconceptional period and foetal development can altered the postnatal performance of the resultant offspring. This nutritional programming can be exerted by maternal and paternal lineages and can affect offspring beyond the F1 generation. Alterations in epigenetic mechanisms have been proposed as the causative link behind the programming trajectories observed in the offspring. Although a clear cause-effect relationship between epigenetic modifications during early development and later offspring phenotype has not been demonstrated in livestock species, strong associations have been reported for some epigenetic marks (e.g. messenger RNA) that are worth exploring as possible predictors of future offspring phenotype. In this review, we shortly describe the main epigenetic mechanisms studied so far in mammals (i.e. mainly in the mouse) thought to be associated with developmental programming, and discuss the few studies available in mammalian herbivores (e.g. cattle) showing the effect of nutrition on epigenetic marks and the associated phenotype. Clearly, there is a need to develop research on nutritional strategies capable of modulating the epigenetic machinery with positive influence on the phenotype of livestock herbivores. This type of research is needed to alleviate the challenges currently faced by the livestock industry (e.g. impaired fertility of high-yielding dairy cows). This in turn will have a positive influence on animal welfare and productivity of livestock enterprises.
\end{abstract}

Keywords: environment, feed, ruminants, reproduction, phenotype

\section{Implications}

The nutritional environment before birth can affect the postnatal performance of offspring. This is believed to be due to alterations exerted by nutrients on the way genes are set to be expressed, resulting in developmental trajectories that have repercussions on postnatal development. This developmental programming we believe need to be considered when developing nutritional strategies in herbivores. The application of this concept will contribute towards a more sustainable, efficient livestock production, which is critical to achieve food security for the rapid population growth predicted for this century.

\section{Introduction}

There is an increasing evidence of the role of parental nutrition and environmental conditions, from periods preceeding conception and throughout gestation, on offspring

\footnotetext{
${ }^{\dagger}$ E-mail: pascale.chavatte-palmer@inra.fr
}

phenotypic development in humans and laboratory animal models but also in domestic mammals (Feeney et al., 2014), including ruminants (Bell and Greenwood, 2016) and horses (Chavatte-Palmer et al., 2016). This phenomenon, also called Developmental Origins of Health and Disease (DOHAD) has been linked to epigenetic mechanisms, considered as the organism's memory of past metabolic and environmental events, to the point that often the two concepts are believed to be highly related.

Direct substantiation that alterations in epigenetic marks are the causative link between maternal or even paternal nutrition and offspring phenotype in mammalian herbivores is currently scarce. Nevertheless, a good understanding of the effect of nutrition and nutriments on the epigenetic machinery may help to predict, prevent or possibly improve phenotypic outcomes. This is a major point considering the current challenges faced by the livestock industry, including alleviation of the decreased fertility in dairy cows, reduction of greenhouse gas emissions from ruminants and the development of nutritional strategies that can cope with climatic changes, especially in ruminants (Soussana et al., 2012). 
After presenting epigenetic processes, this review will focus on the potential epigenetic effects of some nutritional strategies currently used in mammalian herbivores. Therefore, we will use examples where epigenetic outcomes were effectively demonstrated supporting the proposition that the epigenetic bioactivity of feedstuffs and their potential effects on multi-generational or even transgenerational phenotypes should be considered when designing new nutritional strategies in herbivores.

\section{Epigenetic processes}

Epigenetic mechanisms are defined as heritable changes affecting gene and genome function that are inherited through mitosis and probably meiosis and do not involve changes in the DNA sequence. These mechanisms as described below are essential during gametogenesis, early embryonic development and subsequent cellular differentiation, whereby they reinforce cell decisions to commit to different fates, and sustain expression of different sets of genes, by making this decision irreversible. Epigenetic marks thus make possible to maintain all the cell lineages sharing a single genome in a single individual. Besides their role in normal cellular differentiation, epigenetic marks could be modified by environmental factors (e.g. nutrition, exposure to drugs or pollutants, stress, etc.) and can be considered as the memory of the cell. Moreover, some major developmental events depend on epigenetic factors, such as $X$ chromosome inactivation in females and regulation of imprinted genes for which only one parental allele is expressed in the offspring.

The role of epigenetic mechanisms leading to the building up of phenotypes in large animals have been described previously (Jammes et al., 2011). Epigenetic mechanisms include but are not limited to DNA methylation, posttranslational modifications (PTMs) of histones and small and large non-coding RNAs. Collectively, these mechanisms provide specific chromatin remodelling and select the genomic information that will be transcribed into functional attributes.

\section{Deoxyribonucleic acid methylation}

Deoxyribonucleic acid methylation is the most stable and most studied epigenetic modification. In mammals, DNA methylation takes place predominantly on cytosine residues of $\mathrm{CpG}$ dinucleotides. Cytosine methylation results from the transfer of a methyl group from S-adenosylmethionine (SAM, the universal methyl group donor) to the carbon-5 position of the cytosine ring. The family of enzymes responsible for DNA methylation are DNA methyltransferases (DNMTs). DMNT1 contributes to maintenance of DNA methylation during DNA replication and cell mitosis, ensuring heritability of the methylation status. DNMT1 preferentially binds to hemimethylated DNA and copies the DNA methylation of the parental strand to a newly replicated strand. The de novo DNMTs are DNMT3a, DNMT3b and the co-factor DNMT3L. DNMT3a and DNMT3b methylate DNA during embryogenesis and cell differentiation as well as gametogenesis and in response to environmental challenges. DNMT3L lacks a catalytic domain and is proposed to play the role of co-factor, enabling the de novo methylation function of DNAMT3a and DNMT3b.

The genome-wide distribution of DNA methylation is not homogenous and does not have the same effects on gene transcription regardless of its occurrence in promoters, enhancers, gene bodies, CpG rich-regions (namely CpG islands (CGIs)), flanking CGls or in $\mathrm{CpG}$-poor regions. From the whole genome DNA methylation analysis, it is currently accepted that CGIs often overlap with promoter regions and are unmethylated. When they become methylated, they robustly repress transcription as notably seen in X-chromosome inactivation and genomic imprinting. CG-poor promoters display tissue-specific methylation patterns and there is an inverse correlation between methylation at these promoters and transcription. On the contrary, intragenic methylation positively correlates with transcription. Intergenic methylation was often associated with silencing of repetitive DNA and transposable elements and is involved in the maintenance of genome stability (Jones, 2012).

\section{Post-translational modifications of Histone tails}

Histone proteins are structural elements involved in the nucleosome formation and DNA package into chromatin. Histones can be submitted to many post-translational modifications (PTMs) affecting mainly the $\mathrm{N}$-terminal tails of core histones, including acetylation (lysine), methylation (lysine and arginine), phosphorylation (serine and threonine), ADP ribosylation, sumoylation (lysine), ubiquitylation (lysine), butyrylation, citrullination, crotonylation, formylation, proline isomerization and propionylation (Prakash and Fournier, 2018). PTMs are dynamic and reversible processes. The writing, reading and erasing of these groups are insured by key protein families that control epigenetic signalling. The 'Histone Code' hypothesis, whereby distinct histone modifications, on one or more tails, act sequentially or in combination to form a 'histone code' that is read by other proteins to bring about distinct downstream events, has been proposed (Strahl and Allis, 2000). Thus, the presence of these different chemical groups in histone tails greatly influences the histone-DNA interactions and defines chromatin structure affecting gene expression.

Within the PTMs, histone acetylation and histone methylation are the most studied mechanisms in relation with the nutritional status of individuals. Histone acetylation is regulated by the balanced action of histone acetyltransferase and histone deacetylases, largely studied for their potential therapeutic use as anti-cancerous agents. Acetylation of histone tails loosens the histone-DNA interactions, thus enabling the DNA access to transcription machinery leading to gene expression, whereas deacetylation of histone tails strengthens the interactions of histones with DNA and is generally associated with gene repression. Histone methylation levels are also dynamically regulated, such as acetylation of histones, by histone methyltransferases and 
histone demethylases. Lysine residues (K4, 9, 27, 36 and 79 for $\mathrm{H} 3$; $\mathrm{K} 2 \mathrm{O}$ for $\mathrm{H} 4$ ) can be mono-, di- or tri-methylated, whereas argine residues can become only mono-methylated. As for DNA methylation, SAM is required as a methyl donor for histone methylation. The effect of this PTM depends on both the modified residue and the extent of methylation: methylation of histone $\mathrm{H} 3$ on lysine 4 and 36 is related to an open chromatin structure and thus, an active transcriptional state, whereas H3K9 and H3K27 methylation recruits proteins that compact chromatin, which generally results in gene silencing.

\section{Non-coding RNA}

Only about $20 \%$ of gene transcription across the mammalian genome is associated with protein-coding genes indicating that $\sim 80 \%$ of transcripts are non-coding (Nolte-'t Hoen et al., 2015). Non-coding RNAs include the small RNAs (sncRNAs; $<200$ nucleotides) consisting mainly of microRNAs (miRNAs, 19-24 nucleotides long), short interfering RNAs, Piwi-interacting RNAs, small nucleolar RNAs and the long non-coding RNAs (ICRNAs).

The most studied family of sncRNAs is the miRNAs, defined as endogenous, single-strand, non-coding sncRNAs that act at the post-transcriptional level by binding target complementary sequences of messenger RNAs. Their precursors are large primary-miRNAs generated by Pol-II mediated transcription that are subsequently processed in the nucleus to long premature miRNAs and subsequently cleaved by the DICER enzyme (RNAse type III enzyme) in the cytoplasm. After introduction in the RNA-induced silencing complex, the complementary mRNA sequences are targeted and either degraded or their translation inhibited. MiRNAs can remain in the cell (intra-cellular miRNAs) but also be transferred to the extra-cellular fluid compartments either free, in exosomes, in apoptotic bodies, or in association with high-density lipoproteins or bound to RNA-binding proteins (Rome, 2015). These extra-cellular miRNAs are disseminated and target other organs (Nolte-'t Hoen et al., 2015).

The miRNAs are well conserved among species (Chen and Rajewsky, 2007). They regulate gene expression through multiple pathways. Most miRNAs have several targets (Ross and Davis, 2014) and may also interact with other RNAs that are not their direct target to modulate gene expression (Pasquinelli, 2012). Some miRNAs have been shown to be involved in global DNA hypomethylation as they target DNMTs in 3 'untranslated regions of genes. For example, in cattle, miRNA-152 was shown to target DNMT1 (Wang et al., 2014).

Extra-cellular miRNAs vary depending on the individual's nutritional status as a result of interactions with the gut flora, with specific variation of the same miRNAs in the stools and in the blood of individuals in response to specific nutriments, but also as a response to specific properties of nutriments, such as anti-inflammatory activity (Rome, 2015). Studies also indicate that miRNAs contained in nutriments may also cross the intestinal barrier and be transported to target organs such as the liver or the pancreas, where they can induce metabolic responses (Nolte-'t Hoen et al., 2015). Thus, the quantity and the composition of miRNA containing extracellular vesicles correlate well with many physiological and pathological conditions (Delage and Dashwood, 2008) and they are obvious candidates as biomarkers and/or to modulate phenotypes in domestic species (Rome, 2015).

Long non-coding RNAs (>200 nucleotides) are very diverse and poorly conserved among species (Ma et al., 2013). They are also largely involved in transcriptional regulation. The most studied IncRNAs are involved in biological process such as $X$ chromosome inactivation in females and genome imprinting (Borensztein et al., 2017). The molecular mechanisms whereby these IncRNAs act are very complex and specific of each locus; generally, the production of IncRNA drives a local transcriptional silencing (Ma et al., 2013).

\section{Nutritional recommendations and dietary strategies}

In the recent literature, research has focused on adjusting nutritional recommendations for herbivores to adapt to global warming, reduce the $\mathrm{C}$ footprint of dairy cattle (Wilkinson and Garnsworthy, 2016) and enhance cow health, fertility and welfare (Sordillo, 2016; McGuffey, 2017; Lean et al., 2018).

Recommendations for reducing $\mathrm{C}$ footprint in dairy cattle include the use of maize silage, forage and rough feed (Wilkinson and Garnsworthy, 2016). This increase in dietary fibre, proposed in ruminants, is also proposed in horses where the supplementation of pregnant mares with cereal concentrates is common (Vander Heyden et al., 2013; Winkelsett et al., 2005). Indeed, supplementation with carbohydrates in pregnant mares has been associated with increased osteoarticular pathology and impaired glucose homeostasis in offspring (Peugnet et al., 2016). In ruminants, diets high in dietary fibre reduce the proportion of methionine and lysine in the duodenum, important amino acids (AA) that have been considered the most limiting AA in North American diets for lactating cows (Lean et al., 2018).

In view of reducing the costs and the environmental impact in terms of nitrogen output in manure, the use of diets with reduced proteins are currently being considered for ruminant nutrition (Sinclair et al., 2014). In a recent metaanalysis, protein restriction in dairy cows was shown to have varying effects on milk yield and health with no significant effect on fertility. Protected AA supplementation (in particular methionine, lysine and histidine) in ruminant nutrition have been used for many years to improve post-absorptive AA balance.

In addition, the use of phytonutriments is being explored in ruminants due to their bioactive properties such as improving immune responses, reducing oxidative stress and regulating insulin secretion and sensitivity (Oh et al., 2017).

\section{Epigenetic effects of nutrients: importance of one-carbon metabolism}

The above-mentioned feeding practices may induce epigenetic modifications that could subsequently affect parental gametes, embryo development and phenotype and performance of 
Chavatte-Palmer, Velazquez, Jammes and Duranthon

Table 1 Nutritional factors relevant to herbivore nutrition and their epigenetic roles in animal and human research, updated from Delage and Dashwood (2008); Canani et al. (2011)

\begin{tabular}{|c|c|c|c|}
\hline Nutrient categories & Nutritional factor & Sources & Epigenetic mechanism \\
\hline Fatty acids & Butyrate, short chain fatty acids & Digestion of crude fibres & Histone modifications \\
\hline $\begin{array}{l}\text { Factors involved in the } \\
\text { one-carbon } \\
\text { metabolism }\end{array}$ & $\begin{array}{l}\text { Methionine } \\
\text { arginine /citrullin } \\
\text { folic acid betaine } \\
\text { choline } \\
\text { Vitamins } B_{2}, B_{6} \text { and } B_{12}\end{array}$ & & DNA methylation \\
\hline \multirow[t]{16}{*}{ Spices or herbal extracts } & Anacardic acid & Cashew nuts & Histone modifications \\
\hline & Butein & Rhus verniciflua (stems) & Histone modifications \\
\hline & Curcumin (polyphenol) & Curcuma longa (turmeric roots) & microRNA, histone modifications \\
\hline & Diallyl disulfide, allyl mercaptan & Garlic & Histone modifications \\
\hline & Dihydrocoumarin & Melilotus officinalis (sweet clover) & Histone modifications \\
\hline & Fisetin & Rhus toxicodendron (leaves) & Histone modifications \\
\hline & Garcinol & Garcina indica (fruit) & Histone modifications \\
\hline & Genistein (polyphenol) & lupin, fava beans, soybeans, kudzu, psoralea & DNA methylation \\
\hline & Isoliquiritigenin & Glycyrrhiza glabra (licorice) & Histone modifications \\
\hline & Luteolin & Sweet red pepper, celery, parsley & Histone modifications \\
\hline & 6-methylsulfinyl-hexyl isothiocyanate & Horseradish & Histone modifications \\
\hline & Piceatannol & Blueberries & Histone modifications \\
\hline & Quercetin (polyphenol) & Apple, tea, onion, nuts, berries & microRNA, histone modifications \\
\hline & Resveratrol (polyphenol) & Red grapes, eucalyptus, spruce & microRNA, histone modifications \\
\hline & Sulforaphane & Broccoli & Histone modifications \\
\hline & Theophylline & Black and green tea & Histone modifications \\
\hline \multirow[t]{3}{*}{ Metals } & Copper & Ubiquitous & Histone modifications \\
\hline & Nickel & Ubiquitous & Histone modifications \\
\hline & Zinc & Ubiquitous & \\
\hline \multirow[t]{3}{*}{ General dietary changes } & High fat diet & DNA methylation & \\
\hline & Methyl deficiency & & MicroRNA \\
\hline & Protein restriction & & $\begin{array}{l}\text { DNA methylation and histone } \\
\text { modifications }\end{array}$ \\
\hline Retinoic acid & Treatment with retinoic acid & & $\begin{array}{l}\text { DNA methylation and histone } \\
\text { modifications }\end{array}$ \\
\hline
\end{tabular}

offspring. Indeed, epigenetic mechanisms elicited by nutritional factors are numerous (Delage and Dashwood, 2008; Canani et al., 2011; Ross and Davis, 2014) (Table 1). Factors in herbivore and particularly ruminant nutrition that could possibly induce epigenetic modifications are discussed below.

Of particular interest is methionine as a precursor of SAM. Indeed, SAM is not only the primary methyl donor for DNA methylation, but also for protein and histone methylation. $\mathrm{S}$-adenosylmethionine is a species generated in the cyclical cellular process called one-carbon metabolism. One-carbon metabolism is catalysed by several enzymes in the presence of dietary micronutrients, including folate, choline, betaine and cofactors such as $B$ vitamins $\left(B_{12}, B_{6}\right.$ and $\left.B_{2}\right)$. Thus, any imbalance in these nutritional factors may possibly affect epigenetic marks.

\section{Consequences on developmental programming}

Evidence of prenatal programming of production traits in mammalian herbivores through maternal nutrition and metabolic conditions have been recently reviewed elsewhere (Feeney et al., 2014; Bell and Greenwood, 2016; ChavattePalmer et al., 2016). Nevertheless, studies where epigenetic marks have been analysed in response to nutritional intervention during development, in order to understand the mechanistic role of specific nutriments, remain scarce. The following section presents selected examples from animal and human studies as proof of concept for epigenetic inheritance of phenotype. Where available, we will highlight studies in herbivores where demonstration of epigenetic mechanisms has been established.

\section{Gamete quality}

Two phases of whole epigenome 'reprograming', and especially DNA methylome reprograming, have been identified during the life of an individual. The first one takes place during gametogenesis and the second one during the early embryo development. According to data obtained in mouse models, highly methylated primordial germ cells are progressively demethylated during their proliferation and migration phases towards the still undifferentiated foetal gonads (Smallwood and Kelsey, 2012). At the time of sex determination, PGCs are thus poorly methylated in the foetal gonads. Then, de novo methylation occurs but at different times for male and female germ cells. In male germ cells, 
de novo DNA methylation occurs in foetal prospermatogonia arrested in mitosis. At birth, male germ cells methylome has already been re-established and will be maintained during the individual's life by methylation maintenance activity during the proliferation phase (Smallwood and Kelsey, 2012). Conversely, de novo methylation in female germ cells only occurs after birth during the concomitant phases of oocyte and follicular growth, when germ cells do not proliferate and thus does not require maintenance activity. Beyond these differences, the final distribution of methylated CpGs in the genome differs between oocyte and sperm (Stewart et al., 2016). Among the differences, regions involved in the regulation of imprinted genes are differentially methylated during oogenesis and spermatogenesis.

Histone modifications are also very dynamic during spermatogenesis and are associated with incorporation of highly sperm-specific histone variants (Ly et al., 2015). Finally, the majority of histones are removed and replaced by protamines. The remaining histones and other chromatin proteins are located in structurally and transcriptionally relevant positions in the genome and carry diverse PTM relevant to the control of embryonic gene expression (Meyer et al., 2017).

The oocyte nucleus is also a carrier of epigenetic information and recent evidence revealed that large domains labelled with specific histone modifications during oogenesis are inherited by the early embryo's genome and may be responsible for early embryonic gene expression (Dahl et al., 2016).

\section{Effects through the paternal germline}

Epidemiological data in humans demonstrate hereditary transmission of metabolic traits though the paternal germ line. For example, children of males whose mothers underwent to severe undernutrition while pregnant during the Amsterdam famine in the winter of 1944-1945 had increased adiposity compared with controls born before or conceived after the famine (Veenendaal et al., 2013). Such paternal transmission of metabolic traits has also been demonstrated in rodent models, with many nutritional, metabolic or stress-linked conditions in males associated with offspring phenotypic and epigenetic modifications (Carone et al., 2010). Modifications in sperm include changes in DNA methylation (Lambrot et al., 2013; Martinez et al., 2014), histone composition (Terashima et al., 2015) but also in sperm miRNA. In an elegant experiment in rodents, it was shown that the offspring of nutritionally induced obese, diabetic male mice also developed obesity. The injection of miRNA isolated from the sperm of these obese males into one cell embryos that were subsequently transferred to control females induced the same phenotype, highlighting the important role of sperm miRNA (Grandjean et al., 2015).

In domestic animals, epigenetic modifications in sperm were associated with fertility, age or environment (Rahman et al., 2014; Kutchy et al., 2018; Lambert et al., 2018). More recently, semen from high and low fertility bulls was characterized for its DNA methylation signatures and used to produce embryos by in vitro fertilization. Despite similar morphology and development to the blastocyst stage, preimplantation embryos derived from high and low fertility bulls displayed significant transcriptomic differences (Kropp et al., 2017). To our knowledge, no studies have been performed so far to determine the effect of nutrition on epigenetic maturity of male gametes in domesticated animals and its consequence on subsequent offspring.

\section{Embryo quality}

The second genome-wide epigenetic reprograming takes place during early embryonic development. It starts at fertilization, when both parental genomes meet in the same oocyte inherited cytoplasm. It is first marked by the replacement of sperm protamines by histones (in contrast to what happens during spermiogenesis), together with an overall DNA demethylation accompanied by important histone modifications. DNA demethylation affects both paternal and maternal genomes at different times, and by partially different mechanisms (Canovas and Ross, 2016). In the mouse embryo, the average DNA methylation reaches its lowest level at the blastocyst stage. DNA methylation then considerably increases in the epiblast and to a lesser extent in the extraembryonic lineages (visceral endoderm and trophectoderm), which correlates with a sharp increase in the expression of de novo methylase enzymes in the epiblast (Zhang et al., 2018). Histones are also subject to massive reprograming during early development with a tendency to the removal of transcription-repressive marks and their replacement by rather permissive ones. These modifications correlate with and are necessary to the transcriptional activation of the newly formed embryonic genome.

Methionine is required for normal developmental of the bovine embryo. Using ethionine, a compound that blocks the metabolism of methionine in the One-carbon cycle, it was shown that methionine was necessary for development from the morula to the blastocyst stage (Ikeda et al., 2012). Addition of SAM to the culture media restored development to the blastocyst stage. Subsequently, the effects of maternal supplementation on gene expression at the blastocyst stage were evaluated in embryos recovered from cows supplemented with different levels of methionine $(1.89 \%$ v. $2.43 \%$ of metabolizable protein) from calving to embryo collection (Penagaricano et al., 2013). The number of recovered embryos and their quality were not affected (Wiltbank et al., 2014) but RNA sequencing analysis of resultant high quality embryos revealed that the small increase in methionine supplementation induced important down-regulation of genes involved in embryo development and immune responses. One of the two upregulated genes reported coded for apolipoprotein L, 3 like, which is involved in transport and metabolism of lipids and cholesterol. The authors hypothesized that as the concentrations of methionine, histidine and lysine are rate limiting in the uterine fluids of pregnant cows at the time of embryonic elongation (Hugentobler et al., 2007), these effects may be beneficial. Subsequent work showed in a limited number of animals that methionine 
supplementation before and 30 days after calving reduced blastocyst methylation, whereas methionine supplementation at the time of follicular growth and embryo production did not affect methylation but increased lipid contents of blastocysts (Acosta et al., 2016).

\section{Placental function}

In domestic herbivores, the placental structure is classified as epitheliochorial, that is, the chorion (foetal placenta) faces the maternal uterine endometrium. This contrasts with the hemochorial placenta of rodents and primates, where the chorion is directly in contact with maternal blood. Nutrient transport across the placenta relies on a wide variety of mechanisms, involving in particular passive and active transporters. Transplacental transfers are regulated by maternal nutrition: the placenta acts as a sensor to nutrient availability through signalling pathways such as the mammalian target of rapamycin (mTOR) complex that regulates AA-transport or the peroxisome proliferatoractivated receptor $\gamma$ (PPAR $\gamma$ ) involved in the regulation of lipid pathways. Moreover, the placenta is an endocrine organ that produces growth factors such as the maternally imprinted IGF2 and a large variety of hormones, including steroid hormones.

Maternal nutrition with nutriments that affect epigenetic marks may induce direct effects on placental function, acting on transporters, placental sensors or growth factors and hormones or affect foetal development through the action of active compounds on the foetus.

Indeed, pregnant ewe supplementation with protected methionine in the last month of gestation produced lambs that tended to be heavier than non-treated controls (Liu et al., 2016). Similarly, in dairy cows, treatment with protected methionine in the last month of gestation resulted in increased plasma methionine concentrations (by 29\%), maternal food intake, maternal plasma insulin concentrations and calf birth weight. These incremental changes were associated with upregulation of placental genes involved in neutral $A A$ and glucose transport together with increased gene and protein expression of mTOR (Batistel et al., 2017). In these example, DNA methylation was not explored and it is thus difficult to conclude whether effects were mediated by epigenetic mechanisms.

\section{Maternal diet and long-term effect: foetal and post-natal development and health}

In sheep, maternal nutrition (corn diet $v$. hay) in the second half of gestation significantly reduced the expression of imprinted (H19, MEG8, PEG1, DLK1 and IGF2R) and DNMT genes in the muscles of late pregnancy foetuses (Lan et al., 2013). The authors suggested that the higher gene expression in the hay group could be related to a reduced availability of dietary methionine in hay. Indeed, higher methylation was observed for the paternally imprinted IGF2R in the muscle of offspring from corn-fed dams.

Similarly, in Angus-cross beef cattle, a high-starch, cornbased maternal diet was shown to increase calf birthweight compared with calves born to dams fed an isocaloric grass hay based diet (Radunz et al., 2012). A 2-year old offspring also had modified glucose and insulin metabolism as well as lower marbling scores and reduced intramuscular lipid contents. These were associated with increased expression of imprinted genes in muscle, together with increased expression of DNMT3a (Wang et al., 2015).

Although these studies seem to indicate that DNA methylation is a major mechanism explaining the observed effects, a combination of different epigenetic mechanisms is likely to occur. Indeed, supplementation of beef cows with grain mix in the last third of gestation was shown to increase feed intake and reduce basal plasma insulin in offspring with no significant effects on marbling score and only moderate modification in gene expression in Longissimus muscle (Moisa et al., 2015). Nevertheless, downregulation of the anti-adipogenic miRNA-34a was observed in the muscle of the offspring of moderately supplemented cows. Furthermore, an interaction between maternal diet and weaning time was observed for miRNAs involved in the regulation of adipogenesis and insulin resistance (Moisa et al., 2016).

Generally, dietary supplementation is used in the peripartum period in order to prevent or limit the negative energy balance usually observed in high-yielding dairy cows. As previously described, methionine participates to the 1-C metabolism and to synthesis of SAM. A rumen-protected methionine supplementation to the diet given to Holstein cows throughout the peripartum period was shown to upregulate PPAR $\alpha$ gene expression and its target genes (ANGPTL4, FGF21 and PCK1) in liver (Osorio et al., 2016) associated with improved lipid metabolism and immune function (Li et al., 2016). Moreover, methionine supplementation induced a decrease in global hepatic DNA methylation and an increase in the methylation of $\mathrm{CpG}$ in PPAR $\alpha$ promoter region (Osorio et al., 2016). This was the first study to demonstrate an epigenetic effects of methionine supplementation on adult tissues in ruminants. Nevertheless, the mechanistic connections between global DNA and region-specific PPAR $\alpha$ methylation with PPAR $\alpha$ gene expression and functional outcomes in liver remain to be elucidated. Moreover, follow up of the resultant offspring will be also beneficial to determine possible multigenerational effects and the associated epigenetic mechanisms.

Diets rich in folic acid or/and vitamin $B_{12}$ have complex effect on lactation performance and dry matter intake, with an increase in plasma glucose and a decrease in hepatic lipids. In sheep, restricting the supply of vitamin $B_{12}$ and folate during the periconceptional period led to widespread epigenetic alterations to liver DNA methylation in offspring and modified adult health-related phenotypes (Sinclair et al., 2007). Thus, in dairy cows, it would also be interesting to evaluate the effects of maternal folate/vitamin $B_{12}$ supplementation diet during the periconceptional period on offspring health. Taking into account that around conception, embryo development competes for nutrients with mammary gland in dairy cows, it was demonstrated that females born to mothers that were lactating while pregnant produced less milk, lived shorter and were metabolically less efficient than 
Epigenetics, programming and nutrition

females whose foetal life developed in the absence of maternal lactation (Gonzalez-Recio et al., 2012). Although these multigenerationnal effects are relatively low, they should not be ignored and a vitamin-supplemented diet could be a positive nutritional strategy to be used.

\section{Epigenetics in large animals: needs for further research}

Epigenetic research is less developed in farm animals compared with humans or laboratory animals such as rodents due to technical difficulties because tools are as yet scarce, although recent progress has made available high throughput methylome analyses of embryos and somatic tissues (Doherty and Couldrey, 2014; Kiefer et al., 2016). This is further complicated by issues on funding availability and lack of scientific recognition. It is clear that genomics alone does not account for heritable variation in production traits and considering epigenetic regulation in animal selection could improve the prediction of phenotypes and enable a better evaluation of individual genitors (Jammes et al., 2011).

As a first approach, the potential use of epigenetic marks in embryo biopsies, in placenta or in newborn blood as predictive biomarkers of offspring phenotype could be explored. The monitoring of changes in epigenetic marks in individual animals could also be used as tools to monitor responses to dietary interventions in the dam or in the early post-natal period, before obvious phenotypic changes are observed. Indeed, it was shown that progressive silencing of Pdx1 gene in the pancreas preceded the clinical onset of diabetes in rats born after intra-uterine growth retardation (Park et al., 2008). Finally, epigenetic marks in sperm such as DNA methylation (Lambrot et al., 2013) or microRNA (Grandjean et al., 2015) may be possibly be used for selection of sires in animal production.

\section{Conclusion}

In the view of the data presented here, nutritional strategies used in animals can affect not only the performance of the animals, but also the epigenetic marks of themselves and their progeny. So far, the only transgenerational study of transmission of epigenetic marks in domestic species is in pigs (Braunschweig et al., 2012) but it is likely that they will also be demonstrated in other domestic animals (Feeney et al., 2014). Thus, the long-term effects on offspring of new nutritional strategies should be evaluated before widely spreading their use in commercial herds. Moreover, the importance of epigenetic markers such as DNA methylation in sperm, placenta or cord blood or measurement of plasma miRNA to predict phenotype must be explored.

\section{Acknowledgements}

The authors belong to the past European COST actions GEMINI FA0702, EPICONCEPT FA1201 and to the current COST action SALAAM BM1308.

\section{Declaration of interest}

The authors have no conflict of interest to declare.

\section{Ethics statement}

This article is a literature review. No ethical approval was required as no experimental work was performed.

\section{Software and data repository resources}

This article is a literature review. No data or model was generated.

\section{References}

Acosta DAV, Denicol AC, Tribulo P, Rivelli MI, Skenandore C, Zhou Z, Luchini D, Correa MN, Hansen PJ and Cardoso FC 2016. Effects of rumen-protected methionine and choline supplementation on the preimplantation embryo in Holstein cows. Theriogenology 85, 1669-1679.

Batistel F, Alharthi AS, Wang L, Parys C, Pan YX, Cardoso FC and Loor JJ 2017. Placentome nutrient transporters and mammalian target of rapamycin signaling proteins are altered by the methionine supply during late gestation in dairy cows and are associated with newborn birth weight. Journal of Nutrition 147, 1640 1647.

Bell AW and Greenwood PL 2016. Prenatal origins of postnatal variation in growth, development and productivity of ruminants. Animal Production Science $56,1217-1232$

Borensztein M, Syx L, Ancelin K, Diabangouaya P, Picard C, Liu T, Liang JB, Vassilev I, Galupa R, Servant N, Barillot E, Surani A, Chen CJ and Heard E 2017. Xist-dependent imprinted $X$ inactivation and the early developmental consequences of its failure. Nature Structural \& Molecular Biology 24, 226-233.

Braunschweig M, Jagannathan V, Gutzwiller A and Bee G 2012. Investigations on transgenerational epigenetic response down the male line in F2 pigs. Plos One 7, e30583.

Canani RB, Costanzo MD, Leone L, Bedogni G, Brambilla P, Cianfarani S, Nobili V, Pietrobelli A and Agostoni C 2011. Epigenetic mechanisms elicited by nutrition in early life. Nutrition Research Reviews 24, 198-205.

Canovas S and Ross PJ 2016. Epigenetics in preimplantation mammalian development. Theriogenology 86, 69-79.

Carone BR, Fauquier L, Habib N, Shea JM, Hart CE, Li R, Bock C, Li C, Gu H, Zamore PD, Meissner A, Weng Z, Hofmann HA, Friedman NM and Rando OJ 2010. Paternally induced transgenerational environmental reprogramming of metabolic gene expression in mammals. Cell 143, 1084-1096.

Chavatte-Palmer P, Robles M, Tarrade A and Duranthon V 2016. Gametes, embryos, and their epigenome: considerations for equine embryo technologies. Journal of Equine Veterinary Science 41, 13-21.

Chen $\mathrm{K}$ and Rajewsky N 2007. The evolution of gene regulation by transcription factors and microRNAs. Nature Reviews Genetics 8, 93-103.

Dahl JA, Jung I, Aanes H, Greggains GD, Manaf A, Lerdrup M, Li G, Kuan S, Li B, Lee $A Y$, Preissl $S$, Jermstad I, Haugen MH, Suganthan R, Bjoras $M$, Hansen K, Dalen KT, Fedorcsak P, Ren B and Klungland A 2016. Broad histone H3K4me3 domains in mouse oocytes modulate maternal-to-zygotic transition. Nature 537, 548-552.

Delage B and Dashwood RH 2008. Dietary manipulation of histone structure and function. Annual Review of Nutrition 28, 347-366.

Doherty R and Couldrey C 2014. Exploring genome wide bisulfite sequencing for DNA methylation analysis in livestock: a technical assessment. Frontiers in Genetics 5, 126.

Feeney A, Nilsson E and Skinner MK 2014. Epigenetics and transgenerational inheritance in domesticated farm animals. Journal of Animal Science and Biotechnology 5, 48.

Gonzalez-Recio 0, Ugarte E and Bach A 2012. Trans-generational effect of maternal lactation during pregnancy: a Holstein cow model. Plos One 7, e51816. Grandjean V, Fourre S, De Abreu DA, Derieppe MA, Remy JJ and Rassoulzadegan M 2015. RNA-mediated paternal heredity of diet-induced obesity and metabolic disorders. Scientific Reports 5, 18193.

Hugentobler SA, Diskin MG, Leese HJ, Humpherson PG, Watson T, Sreenan JM and Morris DG 2007. Amino acids in oviduct and uterine fluid and blood plasma 
during the estrous cycle in the bovine. Molecular Reproduction Development 74, 445-454.

Ikeda S, Sugimoto M and Kume S 2012. Importance of methionine metabolism in morula-to-blastocyst transition in bovine preimplantation embryos. Journal of Reproduction and Development 58, 91-97.

Jammes H, Junien C and Chavatte-Palmer P 2011. Epigenetic control of development and expression of quantitative traits. Reproduction Fertility Development 23, 64-74.

Jones PA 2012. Functions of DNA methylation: islands, start sites, gene bodies and beyond. Nature Reviews Genetics 13, 484-492.

Kiefer $H$, Jouneau $L$, Campion $E$, Rousseau-Ralliard D, Larcher $T$, Martin-Magniette $M-L$, Balzergue $S$, Ledevin $M$, Prezelin A, Chavatte-Palmer $P$, Heyman Y, Richard C, Le Bourhis D, Renard J-P and Jammes H 2016. Altered DNA methylation associated with an abnormal liver phenotype in a cattle model with a high incidence of perinatal pathologies. Scientific Reports 6, 38869.

Kropp J, Carrillo JA, Namous H, Daniels A, Salih SM, Song J and Khatib H 2017. Male fertility status is associated with DNA methylation signatures in sperm and transcriptomic profiles of bovine preimplantation embryos. BMC Genomics 18, 280.

Kutchy NA, Menezes ESB, Chiappetta A, Tan W, Wills RW, Kaya A, Topper E, Moura AA, Perkins AD and Memili E 2018. Acetylation and methylation of sperm histone 3 lysine 27 (H3K27ac and H3K27me3) are associated with bull fertility. Andrologia 50, e12915.

Lambert S, Blondin P, Vigneault C, Labrecque R, Dufort I and Sirard MA 2018. Spermatozoa DNA methylation patterns differ due to peripubertal age in bulls. Theriogenology 106, 21-29.

Lambrot R, Xu C, Saint-Phar S, Chountalos G, Cohen T, Paquet M, Suderman M, Hallett M and Kimmins S 2013. Low paternal dietary folate alters the mouse sperm epigenome and is associated with negative pregnancy outcomes. Nature communications 4, 2889.

Lan X, Cretney EC, Kropp J, Khateeb K, Berg MA, Penagaricano F, Magness R, Radunz AE and Khatib H 2013. Maternal diet during pregnancy induces gene expression and DNA methylation changes in fetal tissues in sheep. Frontiers in Genetics 4, 49.

Lean IJ, de Ondarza MB, Sniffen CJ, Santos JEP and Griswold KE 2018. Metaanalysis to predict the effects of metabolizable amino acids on dairy cattle performance. Journal of Dairy Science 101, 340-364.

Li C, Batistel F, Osorio JS, Drackley JK, Luchini D and Loor JJ 2016. Peripartal rumen-protected methionine supplementation to higher energy diets elicits positive effects on blood neutrophil gene networks, performance and liver lipid content in dairy cows. Journal of Animal Science and Biotechnology 7, 18.

Liu S, Lei J, Hancock S, Scanlan V, Broomfield S, Currie A and Thompson A 2016. Lamb survival, glutathione redox state and immune function of neonates and lambs from periparturient Merino ewes supplemented with rumen-protected methionine. Archives of Animal Nutrition 70, 389-401.

Ly L, Chan D and Trasler JM 2015. Developmental windows of susceptibility for epigenetic inheritance through the male germline. Seminars in Cell and Developmental Biology 43, 96-105.

Ma L, Bajic VB and Zhang Z 2013. On the classification of long non-coding RNAs. RNA Biology 10, 925-933.

Martinez D, Pentinat T, Ribo S, Daviaud C, Bloks VW, Cebria J, Villalmanzo N, Kalko SG, Ramon-Krauel M, Diaz R, Plosch T, Tost J and Jimenez-Chillaron JC 2014. In utero undernutrition in male mice programs liver lipid metabolism in the second-generation offspring involving altered Ixra DNA methylation. Cell Metabolism 19, 941-951.

McGuffey RK 2017. A 100-year review: metabolic modifiers in dairy cattle nutrition. Journal of Dairy Science 100, 10113-10142.

Meyer TJ, Rosenkrantz JL, Carbone L and Chavez SL 2017. Endogenous retroviruses: with us and against us. Frontiers in Chemistry 5, 23.

Moisa SJ, Shike DW, Shoup L and Loor JJ 2016. Maternal plane of nutrition during late-gestation and weaning age alter steer calf longissimus muscle adipogenic microrna and target gene expression. Lipids 51, 123-138.

Moisa SJ, Shike DW, Shoup L, Rodriguez-Zas SL and Loor JJ 2015. Maternal plane of nutrition during late gestation and weaning age alter angus $x$ simmental offspring longissimus muscle transcriptome and intramuscular fat. Plos One 10, e0131478.

Nolte-'t Hoen EN, Van Rooij E, Bushell M, Zhang CY, Dashwood RH, James WP Harris C and Baltimore D 2015. The role of microRNA in nutritional control. Journal of Internal Medicine 278, 99-109.
Oh J, Wall EH, Bravo DM and Hristov AN 2017. Host-mediated effects of phytonutrients in ruminants: a review. Journal of Dairy Science 100, 5974-5983.

Osorio JS, Jacometo CB, Zhou Z, Luchini D, Cardoso FC and Loor JJ 2016. Hepatic global DNA and peroxisome proliferator-activated receptor alpha promoter methylation are altered in peripartal dairy cows fed rumen-protected methionine. Journal of Dairy Science 99, 234-244.

Park JH, Stoffers D, Nicholls RD and Simmons R 2008. Development of type 2 diabetes following intrauterine growth retardation in rats is associated with progressive epigenetic silencing of Pdx1. Journal of Clinical Investigation 118, 2316-2324.

Pasquinelli AE 2012. MicroRNAs and their targets: recognition, regulation and an emerging reciprocal relationship. Nature Reviews Genetics 13, 271-282.

Penagaricano F, Souza AH, Carvalho PD, Driver AM, Gambra R, Kropp J, Hackbart KS, Luchini D, Shaver RD, Wiltbank MC and Khatib H 2013. Effect of maternal methionine supplementation on the transcriptome of bovine preimplantation embryos. Plos One 8, e72302.

Peugnet P, Robles M, Wimel L, Tarrade A and Chavatte-Palmer P 2016. Management of the pregnant mare and long-term consequences on the offspring. Theriogenology 86, 99-109.

Prakash K and Fournier D 2018. Evidence for the implication of the histone code in building the genome structure. Biosystems 164, 49-59.

Radunz AE, Fluharty FL, Relling AE, Felix TL, Shoup LM, Zerby HN and Loerch SC 2012. Prepartum dietary energy source fed to beef cows: II. Effects on progeny postnatal growth, glucose tolerance, and carcass composition. Journal of Animal Science 90, 4962-4974.

Rahman MB, Kamal MM, Rijsselaere T, Vandaele L, Shamsuddin M and Van Soom A 2014. Altered chromatin condensation of heat-stressed spermatozoa perturbs the dynamics of DNA methylation reprogramming in the paternal genome after in vitro fertilisation in cattle. Reproduction, Fertility and Development 26, 1107-1116.

Rome $S$ 2015. Use of miRNAs in biofluids as biomarkers in dietary and lifestyle intervention studies. Genes \& Nutrition 10, 483.

Ross SA and Davis CD 2014. The emerging role of microRNAs and nutrition in modulating health and disease. Annual Review of Nutrition 34, 305-336.

Sinclair KD, Allegrucci C, Singh R, Gardner DS, Sebastian S, Bispham J, Thurston A, Huntley JF, Rees WD, Maloney CA, Lea RG, Craigon J, McEvoy TG and Young LE 2007. DNA methylation, insulin resistance, and blood pressure in offspring determined by maternal periconceptional B vitamin and methionine status. Proceedings of the National Academy of Sciences of the United States of America 104, 19351-19356.

Sinclair KD, Garnsworthy PC, Mann GE and Sinclair LA 2014. Reducing dietary protein in dairy cow diets: implications for nitrogen utilization, milk production, welfare and fertility. Animal 8, 262-274.

Smallwood SA and Kelsey G 2012. De novo DNA methylation: a germ cell perspective. Trends in Genetics 28, 33-42.

Sordillo LM 2016. Nutritional strategies to optimize dairy cattle immunity. Journal of Dairy Science 99, 4967-4982.

Soussana J-F, Fereres E, Long SP, Mohren FGMJ, Pandya-Lorch R, PeltonenSainio P, Porter JR, Rosswall T and von Braun J 2012. A European science plan to sustainably increase food security under climate change. Global Change Biology 18, 3269-3271.

Stewart KR, Veselovska $L$ and Kelsey G 2016. Establishment and functions of DNA methylation in the germline. Epigenomics 8, 1399-1413.

Strahl BD and Allis CD 2000. The language of covalent histone modifications. Nature 403, 41-45.

Terashima M, Barbour S, Ren J, Yu W, Han Y and Muegge K 2015. Effect of high fat diet on paternal sperm histone distribution and male offspring liver gene expression. Epigenetics 10, 861-871.

Vander Heyden L, Lejeune JP, Caudron I, Detilleux J, Sandersen C, Chavatte P, Paris J, Deliege B and Serteyn D 2013. Association of breeding conditions with prevalence of osteochondrosis in foals. Veterinary record 172, 68.

Veenendaal M, Painter R, de Rooij S, Bossuyt P, van der Post J, Gluckman P, Hanson M and Roseboom T 2013. Transgenerational effects of prenatal exposure to the 1944-45 Dutch famine. BJOG: An International Journal of Obstetrics \& Gynaecology 120, 548-554.

Wang J, Bian Y, Wang Z, Li D, Wang C, Li Q and Gao X 2014. MicroRNA-152 regulates DNA methyltransferase 1 and is involved in the development and lactation of mammary glands in dairy cows. Plos One 9, e101358. 
Wang $X$, Lan X, Radunz AE and Khatib H 2015. Maternal nutrition during pregnancy is associated with differential expression of imprinted genes and DNA methyltranfereases in muscle of beef cattle offspring. Journal of Animal Science 93, 35-40.

Wilkinson JM and Garnsworthy PC 2016. Dietary options to reduce the environmental impact of milk production. The Journal of Agricultural Science 155, 334-347.

Wiltbank MC, Garcia-Guerra A, Carvalho PD, Hackbart KS, Bender RW, Souza AH, Toledo MZ, Baez GM, Surjus RS and Sartori R 2014. Effects of energy and protein nutrition in the dam on embryonic development. Animal Reproduction $11,168-182$.

Winkelsett S, Vervuert I, Granel M, Borchers A and Coenen M 2005. Feeding practice in warmblood mares and foals and the incidence to osteochondrosis. Pferdeheilkunde 21, 124-126.

Zhang Y, Xiang Y, Yin Q, Du Z, Peng X, Wang Q, Fidalgo M, Xia W, Li Y, Zhao ZA, Zhang W, Ma J, Xu F, Wang J, Li L and Xie W 2018. Dynamic epigenomic landscapes during early lineage specification in mouse embryos. Nature Genetics 50, 96-105. 